\title{
Resenha: Intonations, de Marissa J. Moorman
}

\section{MATEUS BERGER KUSCHICK*}

\section{Review: Intonations, by Marissa J. Moorman}

MOORMAN, Marissa J. Intonations: a social history of music and nation in Luanda, Angola, from 1945 to recent times. Athens: Ohio University Press, 2008. 320 p.

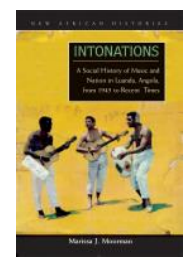

O livro da historiadora norte-americana Marissa J. Moorman é o resultado de sua pesquisa de doutorado realizada em Luanda, Angola, de 1997 a 2005. Intonations aborda a história recente de Angola a partir de um ponto de vista, menos sangrento e mais sonoro, menos sofrido e mais dançante, enfatizando as relações entre a música local e a construção de um sentimento de nação independente, soberana e auto-suficiente culturalmente.

O texto percorre dois momentos cruciais de Angola - o fim do período colonial (1945 a 1975) e o pós-independência (1975 até o início do século XXI) através da produção musical do gênero semba, erigido a símbolo cultural nacional unificador da população a partir de um boom vivenciado por angolanos e angolanas do início dos anos 60 até meados dos 70, período chamado de "Era de Ouro do Semba".

A publicação de M.Moorman (ainda não traduzida para o português) contribui enormemente para o conhecimento da cultura angolana da $2^{\mathrm{a}}$ metade do século XX. Além da ampla pesquisa documental sobre Angola e Portugal, amparada por entrevistas com mais de 40 músicos, jornalistas e pesquisadores locais, a autora

\footnotetext{
* Mateus Berger Kuschick é bacharel em Música/Composição e em Psicologia pela UFRGS e Mestre em Musicologia/Etnomusicologia pela mesma instituição. Atualmente cursa o Doutorado em Música pela UNICAMP.
} 
constrói um quadro detalhado e complexo da história social e musical do país, com foco no entorno da capital Luanda. Um CD, com uma coletânea de 15 canções de artistas representativos do semba, contribui para a compreensão das relações sutis entre músicos e a formação social de Angola.

\section{O semba dos musseques}

O livro, dividido em seis capítulos, apresenta inicialmente uma breve história social dos musseques, bolsões de miséria superpovoados que rodeiam o centro de Luanda. A palavra musseque tem origem no kimbundo (mu seke) que significa areia vermelha. Apresentando muitas vezes péssimas condições de subsistência de sua população, os musseques se constituem em espaços intermediários entre a vida rural e a vida urbana, espaço de recriação de uma música - o semba - portadora de traços dessas duas formas de sociabilidade. Os maiores musseques da cidade, Marçal, Rangel, Prenda, Bairro Operário e Bairro Indígena, abrigaram, desde os anos de 1940, angolanos negros de todas as regiões do país e brancos pobres de Angola ou Portugal, muitos deles vinculados a diversos grupos linguísticos ${ }^{1}$.

Ao dialogar com inúmeros autores que abordaram esse tema, a autora vai aos poucos revelando não apenas suas escolhas teóricas, mas seu posicionamento político ao optar pela análise histórica e cultural a partir do popular. Sua preocupação central é compreender de que modo os habitantes dos musseques formularam respostas culturais inovadoras e improvisadas, traduzindo através de um semba modernizado suas experiências dentro de uma política colonial discriminatória e excludente, "celebrando uma especificidade que refutava dicotomias entre rural/urbano, africano/ocidental (...) proclamando um cosmopolitismo africano que permitia ver além da metrópole colonial”2 2 .

\footnotetext{
${ }^{1}$ Segundo a autora, nos anos 60 e 70, 75\% da população dos musseques se dividia em três línguas: o kimbundo, o umbundo e o kikongo. A predominância era de moradores do sexo masculino e jovens vindos do interior do país.

2 Tradução nossa.
} 
A autora nos lembra que fenômenos sociais podem ter diferentes significados quando vistos por diferentes olhos. Na sua perspectiva, a cultura de uma localidade está constantemente sendo relida, recriada, como uma fonte política dinâmica e pró-ativa. A pesquisadora investiga as relações entre música e política no dia-a-dia dos musseques, onde homens e mulheres de certo modo protagonizaram a formação um "ethos" nacionalista angolano muito mais forte e atuante do que o descrito na "versão oficial" consolidada pelo governo local (MPLA) após a independência. Nesta, os combatentes armados que ocuparam os "mayombes" (florestas) e os líderes políticos exilados foram monumentalizados como símbolos da independência. Na contramão dessa visão hegemônica, Marissa Moorman demonstra que determinados segmentos sociais populares, nesse mesmo período, produziram e traduziram, através da música e de outras práticas culturais, sentidos alternativos sobre a ideia de nação e independência. A autora destaca, por exemplo, o papel de formações culturais e espaços como o grupo musical Ngola Ritmos, o teatro Gexto, além de times de futebol, cinemas e clubes sociais.

O Ngola Ritmos foi fundado em 1947 e seguiu atuante até os anos 70, passando por diversas formações. Carlos 'Liceu' Vieira Dias, violonista, cantor e compositor, é tido como o mentor do grupo ${ }^{3}$. No final dos anos 30, com outros jovens assimilados 4 , ainda chamavam-se Grupo dos Sambas, especializado em música brasileira. Anos mais tarde, criaram o Ngola Ritmos, para "descobrir nossa cultura [a angolana] e valorizá-la".

Além da referência à música rural local (fábulas de diferentes grupos étnicos de Angola, melodias cantadas em funerais e no carnaval), à música brasileira e à da Europa Ocidental, a autora acrescenta como fundamentais para a construção

\footnotetext{
${ }^{3}$ Musicólogos angolanos como Jomo Fortunato e José Redinha creditam a Liceu Vieira Dias o mérito pela transposição de sons de origem rural do país para uma música popular dançante feita com instrumentos ocidentais como o violão, a guitarra e o piano, misturados a instrumentos e ritmos locais, que veio a ser chamada SEMBA.

${ }^{4}$ Define-se assimilados como uma classe de negros(as) e mulatos(as) angolanos(as) que tem na figura paterna homens que ocupam cargos governamentais, militares e religiosos. Em alguns países africanos estabeleceu-se que os ditos assimilados teriam, entre outros privilégios, direito ao voto. Marissa Moorman afirma que essas distinções internas na sociedade angolana entre assimilados e indígenas, apesar de um estatuto jurídico formal, baseavam-se em critérios arbitrários e controversos. Esse grupo de angolanos "assimilados", aculturados por padrões europeus, também povoou os musseques na década de 40 e viria mais tarde assumir a formação do MPLA no final dos anos 50. A classificação "assimilados" foi abolida em Angola após a Revolta de 1961.
} 
do semba como estilo musical as contribuições dos vizinhos congoleses, com suas famosas guitar bands (Franco et le T.P.O.K. Jazz, por exemplo) e o rock dos negros norte-americanos, chegando através dos cinemas. Para "temperar" mais a alquimia de referências formadoras do semba, destaca que a música dos vizinhos do Congo bebia da fonte da música cubana e suas rumbas, sons e derivados. Ou seja, o semba surge de combinações criativas entre essas músicas e adquire contornos peculiares.

À medida que os anos se passaram, música e política foram tornando-se indissociáveis no contexto angolano, e fazer parte de uma banda converteu-se em muitas situações numa atividade perigosa e arriscada. Cada vez mais a valorização das práticas culturais locais através da música representou um ato político de repúdio à dominação colonial portuguesa, levando músicos à prisão pela polícia portuguesa (PIDE), no fim dos anos 50. Liceu foi um deles.

Do mesmo modo, o clube de futebol Bota Fogo, movimentos literários (Vamos Descobrir Angola), jornais, grupos femininos e bandas também concentraram muito da movimentação político-cultural nos anos 60 em Angola.

Quando a repressão colonial aumentou (prisões, assassinatos, violência, intervenções) a conscientização política dos angolanos também avançou. Em 1961, muitos militantes angolanos do MPLA (Movimento Popular para a Libertação de Angola) ou FNLA (Frente Nacional para a Libertação de Angola), principais grupos que lutavam pela independência naquele momento, foram viver fora do país. Porém, quem permaneceu nos musseques acompanhou e participou do boom do semba. $\mathrm{O}$ país viveu uma melhora nas condições de vida da população, em uma temporária prosperidade movida pelo investimento de capital estrangeiro nos setores de minério e petróleo. Marissa destaca os espaços de diversão ao som de semba que embalaram as lutas pró-independência, preenchendo a história recente do país com notas musicais e sorrisos em meio aos rifles e catanas ${ }^{5}$, colaborando diretamente com o projeto nacionalista. Com base nesses fatos, a autora conclui que "nações são práticas históricas através das quais diferenças sociais são inventadas e performatizadas".

\footnotetext{
5 Catana é uma pequena espada bigume, com cabo de madeira, muito usada nas lutas pela independência em países africanos. A catana está representada na bandeira de Angola.
} 


\section{Análises de sembas}

Dos 15 temas presentes no CD anexo ao livro, a autora destaca sete em análises de texto e contexto. Delas, ressalta a importância da recuperação do kimbundo e de outras línguas locais. Segundo Moorman, desde o início do século XX na área urbana já não se falava mais o kimbundo, mas para cantar as músicas, adultos nos anos 60 reaprenderam a língua, usando-a nas canções, mas não na conversação. Por mais que o kimbundo representasse especificidades regionais de uma parte da população rural, sua inserção no semba se deu como negação e reação ao projeto colonial português. Durante décadas o colonizador se referiu ao kimbundo como "linguagem dos cães".

Para além do idioma cantado, Moorman sintetiza: “coisas europeias (não apenas portuguesas) e das américas - instrumentos, tempo de duração das músicas, temas românticos, moda - foram usadas para enfatizar coisas africanas: como histórias locais, a flora e a fauna, parábolas, danças, idiomas. O resultado foi a criação de coisas unicamente angolanas" (p.113). A mensagem que os sembas transmitem, segundo Moorman é muito mais quinestésica do que literal: é uma mensagem compreendida pelo corpo como um todo, principalmente através da dança. “Em Angola, música e dança estiveram, e estão, intimamente ligadas, se não, inseparáveis" (p.117).

No CD anexo, os destaques são: Ngola Ritmos, Os Kiezos, Garda e o Seu Conjunto (formada por mulheres), Duo Ouro Negro, Elias dia Kimuezo e outros. Inovações tecnológicas (principalmente a chegada maciça do rádio e dos meios de gravação e reprodução em vinil) expandiram o semba para muito além dos musseques: chegaram por todo o país, saíram dele e voltaram.

\section{Semba nas rádios de Angola}


Com o conceito de capitalismo sonoro, a autora afirma que "o rádio e a indústria de gravação reterritorializaram a música produzida nos musseques, dando a ela uma presença e um sentido nacionais". Moorman utiliza Benedict Anderson e o conceito de Comunidades Imaginadas para mostrar o importante papel desempenhado pelo rádio e pelas primeiras gravadoras angolanas na divulgação e construção de uma ideia homogênea de angolanidade. O rádio em Angola encurtou as distâncias, criou um novo espaço de convivência e coletividade em torno de si e imprimiu no país um sentido de imediatismo e realismo. A autora traz à tona os DJs e seu papel na difusão dos aparelhos de toca-discos no país e descreve a chegada de selos estrangeiros, que lançaram artistas angolanos no mercado mundial, no ramo da incipiente worldmusic.

Moorman aborda também o chamado "hiato musical" vivido no país após a independência (1975-1990), baseando-se no relato dos entrevistados e em uma qualificada pesquisa historiográfica. Analisa as relações que envolviam a música e a política interna do MPLA, partido político que assumiu o poder do país de 1975 em diante. Descreve detalhes de uma tentativa de golpe (em maio de 1977), quando divergências internas do MPLA somadas à oposição da UNITA, fizeram intensificar a repressão, a violência, a crise e a fome no país de maneira inimaginável. Perseguições, emboscadas, assassinatos, censura. Adolfo Maria, testemunha desse período, declara que “a partir de 1978, Angola encontrou a paz: a paz dos cemitérios e do medo coletivo".

\section{Música angolana no século XXI}

No último capítulo é apresentado um panorama da música feita na Angola do século XXI: seus astros e estrelas, os espaços disponíveis nas cidades, os novos nomes do semba e a explosão do kuduro - gênero musical angolano que incorpora à sonoridade local elementos da música eletrônica e do rap. Assim como na golden age do semba (1961-1975), a música do XXI continua refletindo o dia-a-dia da população do país, transcendendo o sofrimento, construindo novas relações sociais e mostrando que a diversão pode ser subversiva e que a subversão pode ser 
algo divertido. Em suma, pode-se dizer que o kuduro, fusão peculiar entre dança e música impregnada de significado político de denúncia e engajamento, é hoje herdeiro social do semba dos 60. Se ontem o lugar eram os clubes, hoje são as ruas. Se o semba celebrava a iminência da independência, o kuduro celebra a própria sobrevivência e a euforia do pós-guerra.

Intonations aproxima política e cultura de modo inovador. A música angolana dos anos 40 aos 70 do XX "afinou" e projetou uma tomada de consciência do povo, que a autora soube apresentar de maneira rica, detalhada e com posicionamento político. É um texto recomendável não apenas para músicos e etnomusicólogos, mas todos os que querem conhecer um pouco mais da história recente de Angola. 